\title{
Clinical characteristics of children with epilepsy managed at a tertiary hospital in Africa: a retrospective study
}

\author{
Pauline Samia ${ }^{1}$, Arwen Barr ${ }^{2}$, Subira B. Levi ${ }^{3}$, Kirsten A. Donald ${ }^{4}$, Jo M. Wilmshurst ${ }^{(\mathbb{D} 5}$, \\ Charles R. Newton 6 \\ ${ }^{1}$ Department of Paediatrics and Child Health,Aga Khan University, Nairobi, Kenya; ${ }^{2}$ University of \\ Victoria, British Columbia, Canada; ${ }^{3}$ Aga Khan University, Nairobi, Kenya; ${ }^{4}$ Division of Developmental \\ Paediatrics, , ${ }^{5}$ Division of Paediatric Neurology, Department of Paediatrics and Child Health, Red \\ Cross War Memorial Children's Hospital, University of Cape Town, South Africa; ${ }^{6} \mathrm{KEMRI-Wellcome}$ \\ Trust Collaborative Programme, Kilifi, Kenya
}

Corresponding author: Pauline Samia; Email: pauline.samia@gmail.com; Tel:+254 722871067

doi https://doi.org/10.17724/jicna.2019.162

Received: 12 Jan 2019

Revised: 18 Nov 2019

Accepted: 27 Dec 2019

\begin{abstract}
Background:Most children with epilepsy reside in resource-limited regions such as sub-Saharan Africa, where the majority of studies have been conducted in rural areas with limited investigations. Medical records from children with epilepsy seen at an urban hospital in Kenya were examined to provide a comprehensive description of epilepsy in children from this hospital.

Methods:A retrospective observational study was conducted which involved reviewing medical records of 426 epilepsy patients (260 males and 166 females) aged 0 - 18 years, seen in Nairobi, Kenya between February 2011 and December 2014.

Results:The most frequent age at presentation; documented in $29 \%$ was in infancy. Generalized seizures due to structural brain abnormalities were the most common form of epilepsy (28\%). Lennox-Gastaut Syndrome was the most common electroclinical syndrome (7\%). Focal seizures and focal seizures with loss of awareness were identified in $12 \%$ of the population. There were no cases of childhood absence epilepsy in this group. Brain atrophy was the most common MRI finding, occurring in a fifth of the population (20\%), while cystic encephalomalacia occurred in $13 \%$. Half (50\%) of all EEG recordings performed for this cohort were abnormal. Generalized seizures due to structural brain abnormalities and Lennox-Gastaut Syndrome (LGS) were significant predictors of a treatment history of three or more AEDs. At the conclusion of the review period, 16\% of the patients had not visited the clinic for more than 12 months and were considered to be lost to follow-up.

Conclusion:The highest frequency of epilepsy cases was documented in children less than one year of age. Generalized seizures due to structural abnormalities and Lennox-Gastaut syndrome were the most common seizure type and syndrome. Improvement of public awareness of different types of seizures in children may increase identification of children with childhood absence epilepsy.
\end{abstract}

Kewords: epilepsy, children, electroclinical syndrome, Kenya, sub-saharan Africa

(c) Samia P; licensee JICNA

\section{Background}

The has identified epilepsy as presenting a significant burden as measured by Disability-adjusted life years (DALY) [1]. Epilepsy affects approximately 50-70 million peo- ple worldwide [1-3] and up to $80 \%$ of those affected reside in low and middle-income countries (LMIC), such as those comprising the majority of Sub-Saharan Africa(SSA) [2][3][4].

According to studies in five SSA countries, the prevalence 


\section{Methods}

Paediatric neurologists and local medical personnel practicing in low-resource settings face multiple challenges. Access to neuroimaging and specialised neurophysiological testing, such as electroencephalography(EEG), is typically concentrated in single centres, usually located in larger cities.

This was a retrospective observational study based on a review of the medical records of children and adolescents (aged 0 - 18 years) with epilepsy who were seen at Aga Khan University Hospital, Nairobi, Kenya between 2011 and 2014. The hospital is an urban academic institution which functions as a primary referral hospital for clients in the vicinity and also acts as a tertiary university hospital with facilities for EEG and neuroimaging. The hospital further provides supportive funding for patients without capacity to pay for such services. Approximately $10 \%$ of patients seen at the paediatric neurology clinic were sponsored by the hospital and another $10 \%$ had their medical costs supported by the National Hospital Insurance Fund (NHIF), Kenya's national health insurance scheme. It is estimated that $65 \%$ of patients seen at this facility are referrals from outside of the Aga Khan University hospital network of facilities.

The patient medical records examined consisted of phys- ical files and as well as information stored on the hospital's electronic databases. Physical files of patients seen at the hospital during this period indicating a history of seizures or diagnosis of epilepsy were obtained from the medical records department using ICD-10 (International Classification of Diseases, Tenth Revision) codes utilized at the time of archiving. From these records, all patients diagnosed with epilepsy, according to the ILAE 2014 definition of epilepsy, were selected for inclusion in the study [13]. According to the ILAE, epilepsy is defined as two or more unprovoked seizures occurring at least 24 hours apart, or one unprovoked seizure with a probability of recurrence determined to be greater than $60 \%$ [13]. Based on this definition, the following patients were excluded from the study: patients presenting with typical simple febrile seizures only; patients with a single seizure episode without an epilepsy syndrome diagnosis or identifiable structural brain abnormality; those with a single provoked seizure in the context of fever or hypocalcemia, for example; as well as those with episodes of syncope only; or non-epileptic, psychogenic seizures solely.

Evaluation for co-morbidities such as attention deficity hyperactivity disorder(ADHD)and autism spectrum disorder(ASD) were made by the paediatric neurologist who assumed care for the children. Screening for these comorbidities was done using National Institute for Children's Health Quality (NICHQ), Vanderbilt Assessment Scales for ADHD and the Diagnostic and Statistical Manual of Mental Disorder, Fifth Edition (DSM V) for ASD. Where other behavioural concerns were identified these children were evaluated by a child psychiatrist. Results of these evaluations were included in patient records. During regular clinic visits data on patient developmental progress was also included in the medical records.

Data on patient sex; age at seizure onset; electroclinical diagnosis; structural brain abnormalities; number and type of ASMs in treatment history; consistency of clinic followup and co-morbidities were extracted as previously documented in the patient's clinical notes. Further data was obtained from clinical notes and technical reports describing imaging and electrophysiological findings. The research assistant who collected and analysed the data was trained and supervised by the paediatric neurologist who assessed and managed the patients.

Electroclinical syndrome diagnoses were determined according to guidelines outlined in the Proposal for Revised Classification of Epilepsies and Epileptic Syndromes, by the Commission on Classification and Terminology of the ILAE [9][10]. Epilepsy that could not be classified as an electroclinical syndrome was described according to seizure type (i.e. generalized or focal) and cause (e.g. structural aetiology) [9].

Age at seizure onset was recorded in months and grouped into one of four periods of onset: i) neonatal - where onset of seizures occurred within the first 28 days of life; ii) infancy - where seizures commenced between 1 and 12 months of life; iii) childhood - where seizures began between 12 and 120 months (i.e. 1 - 10 years) of age; and iv) 
adolescence - where onset of seizures occurred between 120 and 216 months of age (i.e. 10 years to 18 years). These groupings were based on WHO age classifications [14][15].

The findings of all EEG reports were counter-checked by the paediatric neurologist. Brain magnetic resonance imaging(MRI) and head computed tomography(CT) reports generated at both external hospitals and Aga Khan University Hospital were counter-checked by one neuroradiologist. Patients who had not visited the clinic for twelve months or longer were defined as being lost to follow-up.

This study was subjected to a full scientific and an expedited ethics review. The Aga Khan University Hospital Ethics Committee gave approval to conduct the study (reference number 2015/REC-27 (vl) dated 29th June 2015). Permission to access records from Aga Khan University Medical Records Department was granted from 30th June 2015 to 29th June 2016. As this was a retrospective review of medical records without direct patient contact, the Institutional Review Board(IRB) did not require patient consent to participate.

In analysing the data, patients were grouped primarily by electroclinical syndrome [9][10]. In cases where an electroclinical diagnosis could not be applied, patients were categorised according to seizure type and aetiology where known [9].

Variables including sex, age at seizure onset, use, results of investigations into structural and electrophysiological brain abnormalities, consistency of clinic follow up and co-morbidities were documented for all patients in the study group and these were analysed using descriptive statistics and presented in frequency tables and distributions.

\section{Results}

A total of 1,106 children were seen at the paediatric neurology clinic between February 2011 and December 2014. Among these were 576 children with a history of seizures, of whom only 426 had a diagnosis of epilepsy and were included in the study as shown in Table 1.

\section{Sex and diagnosis frequency}

The male: female ratio was 1.6:1 (260 males and 166 females), with males comprising $61 \%$ of the study population (Table 1). LGS was the most common electroclinical syndrome. Overall, of all the syndrome and seizure types, generalized seizures associated with structural brain abnormalities was the most frequent form of epilepsy.

\section{Age at seizure onset}

Fifty-six percent of patients $56.6 \%(\mathrm{~N}=241)$ developed seizures between 1 and 10 years of age while $29 \%(\mathrm{~N}=$ 125) of patients developed seizures in infancy (between 1 and 12 months of age.) Fewer patients, 7.5\% $(\mathrm{N}=32)$, presented with seizures for the first time between 10 and 18 years. This data is shown in Table 2 .

\section{Structural and electrophysiological brain abnormalities}

A total of $8.5 \%(\mathrm{~N}=36)$ of patients had no investigation results available on file. The majority of the patients, $86.4 \%(\mathrm{~N}=368)$ had a sleep EEG reported, while approximately half of the study population, $48.8 \%(\mathrm{~N}=208)$ had a brain MRI scan with contrast. Reported findings from the brain MRI scans are summarized in Table 3. Ten children $(4.8 \%)$ who had both brain MRI and head CT reports had their findings included in the brain MRI group. Four among these $(0.9 \%)$ had both normal head CTs and brain MRIs while three children (1.4\%) had delayed myelination on brain MRI. Two children $(0.9 \%)$ had white matter hyperintensities and one child $(0.4 \%)$ had polymicrogyria on brain MRI.

Among those who did not have brain MRI, 19.2\% ( $\mathrm{N}=$ 106) of patients had CT scans, of which $53.4 \%(\mathrm{~N}=57)$ were abnormal. Brain atrophy and hydrocephalus were the most common abnormalities identified in $45.6 \%(\mathrm{~N}=26)$ and $(\mathrm{N}=10) 17.5 \%$ children respectively. A total of $47.2 \%$ $(\mathrm{N}=50)$ had normal head CT reports. In this cohort $26.2 \%$ $(\mathrm{N}=112)$ of children with epilepsy had no neuroimaging records.

A total of 557 EEG recordings were performed for the 426 patients in the study. Among these, 5.9\% of all the EEG recordings $(\mathrm{N}=33)$ demonstrated indeterminate findings, while $43.1 \%(\mathrm{~N}=240)$ of these were normal and $50.1 \%$ $(\mathrm{N}=284)$ were abnormal. Of the abnormal EEG recordings $56.7 \%(\mathrm{~N}=161)$ showed generalized spike wave discharges, $25.3 \%(\mathrm{~N}=72)$ showed focal spike wave discharges while $17.9 \%(\mathrm{~N}=51)$ of abnormal EEG recordings showed slowing activity.

\section{Anti-seizure medication use}

Of the total patient population, $89.4 \%(\mathrm{~N}=381)$ had been treated with one or more ASMs since onset of epilepsy while $10.6 \%(\mathrm{~N}=45)$ of patients had not been on MRI treatment (Table 4). Among those on antiepileptic medication, $42.7 \%(\mathrm{~N}=176)$ of patients been treated with one ASM , 24.2\% ( $\mathrm{N}=100)$ with two ASMs, $17.4 \%(\mathrm{~N}$ $=72)$ with three ASMs and $9.2 \%(\mathrm{~N}=38)$ with four or more ASMs serially. Table 4 summarizes types of ASMs that were utilized in this population in order of frequency. As illustrated above individual patients may have utilized more than one medication. Valproic acid was the most commonly used ASM with 69.4\% usage amongst the study participants, followed by Carbamazepine and Clonazepam with $24.2 \%$ and $20.8 \%$ usage respectively. In contrast, Pregabalin and Gabapentin were the least used (each having been utilized by $0.3 \%$ of study participants).

\section{Co-morbidities}

Of the 426 children, $21.6 \%(\mathrm{~N}=92)$ had psychiatric comorbidities: Among these 10.1\% $(\mathrm{N}=43)$ had ADHD; $8.2 \%$ $(\mathrm{N}=35)$ had ASD; $0.5 \%(\mathrm{~N}=2)$ had mood disorders; $1.2 \%$ $(\mathrm{N}=5)$ had a psychosomatic illness; and $1.6 \%(\mathrm{~N}=7)$ had other behavioural concerns. Further, almost half of the patients with psychiatric co-morbidities $0.9 \%(\mathrm{~N}=40)$ had focal seizures with loss of awareness. Various neurodevelopmental co-morbidities were observed in this study popu- 
Table 1 Distribution of the Epilepsy diagnoses within the study sample, by sex

\begin{tabular}{|c|c|c|c|c|}
\hline Diagnosis & $\begin{array}{l}\text { Total } \\
\mathrm{N}=426 \\
-100 \%\end{array}$ & $\begin{array}{l}\text { Male } \\
N=260 \\
-61 \%\end{array}$ & $\begin{array}{l}\text { Female } \\
\mathrm{N}=166 \\
-39 \%\end{array}$ & Proportion of Cohort \% \\
\hline \multicolumn{5}{|l|}{ Epilepsy syndromes } \\
\hline Lennox-Gastaut syndrome(LGS) & 29 & 18 & 11 & 6.8 \\
\hline Infantile spasms (West Syndrome) & 22 & 12 & 10 & 5.2 \\
\hline Epilepsy with myoclonic astatic seizures(EMA) & 5 & 4 & 1 & 1.2 \\
\hline Juvenile myoclonic epilepsy(JME) & 5 & 1 & 4 & 1.2 \\
\hline Juvenile absence epilepsy(JAE) & 3 & 2 & 1 & 0.7 \\
\hline Childhood epilepsy with centro-temporal spikes(CECTS) & 2 & 2 & 0 & 0.5 \\
\hline Dravet syndrome & 1 & 1 & 0 & 0.2 \\
\hline \multicolumn{5}{|l|}{ Seizure semiologies } \\
\hline Generalized Seizures with structural brain abnormalities & 117 & 76 & 41 & 27.5 \\
\hline Generalized Epilepsies of unknown cause & 99 & 60 & 39 & 23.2 \\
\hline Focal Seizures & 52 & 28 & 24 & 12.2 \\
\hline Focal seizures with loss of awareness & 40 & 26 & 14 & 9.4 \\
\hline Febrile seizures plus & 44 & 24 & 20 & 10.3 \\
\hline Genetic Epilepsy with febrile seizures plus & 7 & 6 & 1 & 1.6 \\
\hline
\end{tabular}

$\mathrm{N}$ represents the number of study participants

Table 2 Distribution of age at seizure onset

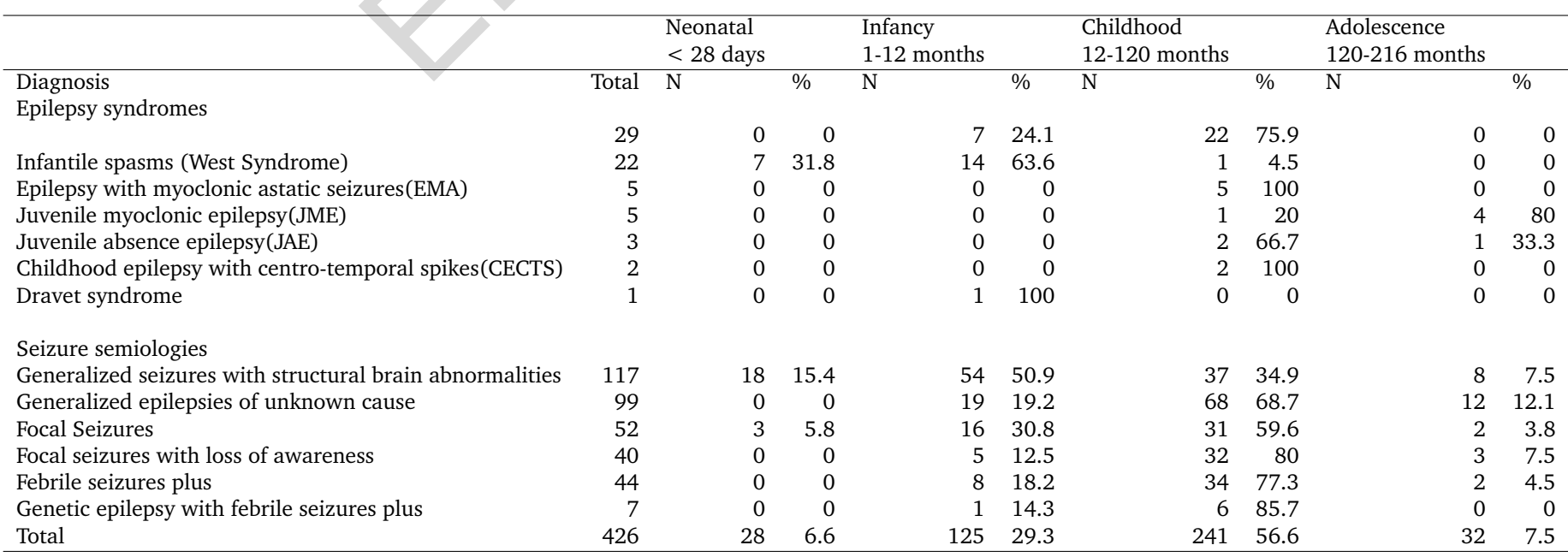

$\mathrm{N}$ represents the number of study participants 
lation. These included developmental delay in $27.9 \%(\mathrm{~N}=$ 119) of patients; speech delay in $17.4 \%(\mathrm{~N}=74)$; intellectual disability in $8.7 \%(\mathrm{~N}=37)$; cerebral palsy in $15.3 \%$ ( $n=65$ ); and developmental milestone regression in $7.8 \%$ $(\mathrm{N}=33)$ of patients. The greatest proportion of neurological co-morbidities was observed among patients with (N $=29)$, including developmental delay in $34.5 \%(\mathrm{~N}=10)$ of patients, speech delay in $20.7 \%(\mathrm{~N}=6)$, intellectual or learning disabilities in $27.6 \%(\mathrm{~N}=8)$, and regression of milestones was in $24 \%(\mathrm{~N}=7)$.

\section{Attrition rates}

At the conclusion of the review period, one patient had died and an additional $16.4 \%(\mathrm{~N}=70)$ of study participants who had not visited the clinic for more than 12 months were considered to be lost to follow-up. In this group there were $60 \%(\mathrm{~N}=42)$ males and $40 \%(\mathrm{~N}=28)$ females. Among these, $41.5 \%(\mathrm{~N}=29)$ were aged less than 24 months at initial presentation to the clinic. The diagnosis of patients lost to follow up is summarized in Table 5 .

\section{Discussion}

In Africa preventable factors such as perinatal insults during complications of delivery, maternal and infant infections and trauma contribute to the high prevalence of epilepsy [16][17][18][19][20][21][22]. Limited access to quality healthcare care facilities and services further negatively impact prevention and management of epilepsy on the continent [19][23][24][25][26][27][28][29][30]. Epilepsy is associated with significant personal and social consequences including increased risk of injury, limited education, unemployment and social ostracism [31][32][33][34][35].

Infants in their first year of life accounted for the highest incidence of epilepsy overall and the highest proportion of paediatric patients presenting with generalized seizures due to structural brain abnormalities. These two observations may be related to the significant proportion of infants who had birth injury and various other congenital brain malformations. These findings are in keeping with a population study by Ellenberg et al showed that the highest incidence of non-febrile seizures occurred within the first year of life [36]. Targeted efforts to identify infants with epilepsy in the first year of life in this context would therefore be important in ameliorating morbidity associated with this condition.

Generalized epilepsy has been found to be the most common kind of epilepsy in many paediatric, and adult population studies [20][21][37]. This was found to be the case among patients in this cohort, a significant proportion of whom had generalized seizures due to structural abnormalities. This observation would be reflective of the fact that members of the cohort attended an urban medical facility where appropriate neuroimaging facilities were available. Data from various parts of rural Kenya regarding children with epilepsy indicate that generalized seizure are the most easily identifiable seizure presentations in the community [38][39]. Studies which reported higher prevalence of fo- cal onset seizures also reported a higher incidence of acute symptomatic seizures in a malaria endemic area [40]. A multi-site population study in the country may help elucidate the distribution of epilepsy seizure types better.

Generalized epilepsy of unknown cause was the second most frequent type of epilepsy observed in this cohort. Other studies in Africa have also demonstrated that the cause of epilepsy can frequently be unknown [41][42][22]. Inability to determine the cause of epilepsy is largely due to financial and diagnostic limitations at the point of care [18]. Further, genetic and metabolic testing is not available locally and performance of these tests by overseas healthcare partners is associated with significant financial costs and time delays as has been our experience. This is particularly noteworthy when considering that Kenya's per capita GDP in 2016 was USD 1,410 [43], meaning that patients lacking medical insurance cover would struggle to access requisite tests such as the early infantile epileptic encephalopathy sequencing panel that costs USD 2000 on average.

Since generalized epilepsy of unknown cause was a frequent observation amongst patients in this cohort, as in other studies, and in light of potential benefits of determining the cause of epilepsy where possible, interventions to improve the quality of and access to local diagnostic facilities such as neuro-imaging, electroencephalography, metabolic and genetic testing would be beneficial to the management of epilepsy patients in sub-Saharan Africa.

Positive family history of febrile seizures in children who presented with atypical febrile seizures allowing a diagnosis of Genetic Epilepsy with febrile seizures plus was rarely determined in this cohort. This could be due to low rates of diagnosis of atypical febrile seizures in this setting or cultural reasons where families rarely discuss seizures in children openly due to associated stigma. Cultural reasons may also contribute to the predilection for more significantly male children presenting for care at this centre.

In this cohort we identified no children with childhood absence epilepsy(CAE) which being a common form of epilepsy, was an unexpected finding [40][44]. This is most likely due to under-recognition and lack of referral of such cases to the neurology teams. It is possible CAE is managed by paediatricians and being generally responsive to widely available first line ASMs, referral in such cases would not be required.

Critically, patients who are lost to follow-up are likely to remain untreated. Long-standing, untreated epilepsy has detrimental and enduring personal and social consequences, including impaired intellectual performance [31][32][33][34][35]. For these reasons, there is an urgent need to determine the reasons for defaulting on clinic follow-up [37]. Findings from these studies which may be applicable to other similar hospital settings would enable this institution to address these specific risk factors and potentially reduce the number of children with epilepsy who remain untreated.

Study limitations 
Table 3 Brain MRI findings in order of frequency

\begin{tabular}{lrr}
\hline Brain findings & Total & Proportion of Cohort \% \\
& $\mathrm{N}=208$ & 26.4 \\
\hline Normal & 55 & 19.7 \\
Brain atrophy & 41 & 12.5 \\
Cystic encephalomalacia & 26 & 9.6 \\
Mesial temporal sclerosis & 20 & 7.7 \\
White matter hyper intensities & 16 & 5.3 \\
Hydrocephalus & 11 & 3.8 \\
Benign enlargement of the subdural space & 8 & 2.9 \\
Periventricular leukomalacia & 6 & 2.9 \\
Agenesis of corpus callosum & 6 & 1.9 \\
Delayed myelination & 4 & 1.5 \\
Tuberous sclerosis complex (sub-ependymal nodules, harmatomas, calcifications) & 1.5 \\
Hemimegalencephaly & 3 & 1.5 \\
Meningeal enhancement & 3 & 0.9 \\
Holoprosencephaly & 3 & 0.9 \\
Schizencephaly & 2 & 0.5 \\
Lissencephaly & 2 & 0.5 \\
Polymicrogyria & 1 & 1 \\
\hline
\end{tabular}

$\mathrm{N}$ represents the number of study participants

Table 4 utilized in epilepsy management

\begin{tabular}{lrr}
\hline Medication & $\mathrm{N}=381$ & Proportion of cohort \% \\
\hline Valproic Acid & 267 & 69.4 \\
Phenobarbital & 77 & 20 \\
Clonazepam & 80 & 20.8 \\
Levetiracetam & 46 & 11.9 \\
Phenytoin & 34 & 8.8 \\
Vigabatrin & 12 & 3.1 \\
Carbamazepine & 93 & 24.2 \\
Lamotrigine & 26 & 6.8 \\
Topiramate & 10 & 2.6 \\
Pregabalin & 1 & 0.3 \\
Gabapentin & 1 & 0.3 \\
Clobazam & 4 & 1 \\
\hline
\end{tabular}

$\mathrm{N}$ represents the number of study participants

Findings presented here represent the context of an urban hospital and would be beneficial to the populations in similar contexts but would not be directly generalizable to most of the sub-Saharan African population who lack access to care and facilities of this nature. Cognitive, motor and behavioural outcomes for the different syndromes or seizure groups were not studied as this information was not measured in a standardised fashion for all the patients in the study population. This was a retrospective study and as such, missing data as well as other factors could impact on the quality of data generated. Future prospective studies in this area should make provision for two reviews of each laboratory investigation and plan to address inter-rater variance.

\section{Conclusions}

The study identified that males comprised the majority of paediatric epilepsy patients seen at this paediatric neurology service while LGS was the most common electroclinical syndrome. Generalized seizures associated with structural brain abnormalities were the most frequent form of epilepsy overall. Half of all EEGs performed displayed abnormalities including generalized spike wave discharges, focal spike wave discharges and slow background activity in decreasing occurrence respectively. Majority of patients had been treated with one ASM only, with valproic acid being most common utilized ASM. Psychiatric co-morbidities were more commonly identified in children with focal seizures while and those with Lennox Gastaut syndrome were more likely to present with developmental delay. The findings from this study hold significant relevance for the improved diagnosis and management of epilepsy among paediatric patients in urban SSA, including need for: greater preventive and diagnostic care predominantly targeting children in the 1 to 10 year age group; increased efforts to address patient attrition rates; and improvement of practitioner and public awareness of common forms of epilepsy to facilitate early detection and appropriate referral and management. This paper's contribution to existing research concerns its potential to address a dearth of recent studies conducted in sub-Saharan Africa describing electro-clinical syndromes or syndrome-associated outcomes among children in the region. Prospective studies may seek to explore precise relationships between specific syndromes and variable such as psychiatric and neuro-developmental co-morbidities and responses to anti-epileptic drugs. 
Table 5 Diagnosis of patients lost to follow up

\begin{tabular}{lrr}
\hline Diagnosis & $\mathrm{N}=70$ & Proportion of cohort \% \\
\hline Focal seizures with loss of awareness & 6 & 8.3 \\
& 5 & 7 \\
Generalized epilepsies of unknown cause & 39 & 55.7 \\
Focal seizures & 4 & 5.7 \\
Epileptic spasms (West syndrome) & 2 & 2.8 \\
Generalized Seizures with structural brain abnormalities & 4 & 5.6 \\
& 2 & 2.8 \\
\hline
\end{tabular}

$\mathrm{N}$ represents the number of study participants

\section{Abbreviations}

ADHD Attention deficity hyperactivity disorder

ASD Autism spectrum disorder

ASM Anti-seizure medication

CAE Childhood absence epilepsy

CECTS Childhood epilepsy with centro-temporal spikes

DALY Disability-adjusted life years

EEG Electroencephalogram

EMA Epilepsy with myoclonic astatis seizures

ILAE International League Against Epilepsy

JAE Juvenile absence epilepsy

JME Juvenile myoclonic epilepsy

LGS Lennox-Gastaut syndrome

LMIC Low and Middle Income Countries

MRI Magnetic resonance imaging

SSA Sub-Saharan Africa

WHO World Health Organization

\section{Acknowledgements}

We wish to acknowledge support provided by James Kaburia (Medical Records Department), Peter Gatiti (Librarian at Aga Khan University, Nairobi), Maureen Kanana for statistical support and Andrew Levi, policy analyst at the Kenya Institute for Public Policy Research and Analysis for technical contributions to the revision of this paper.

\section{Competing interests}

The authors declare no competing interests. No funding was sought for this study. The Aga Khan University catered for research time for PS, AB and SL.

\section{Authors' contributions}

PS designed the study. $\mathrm{AB}$ and SL analysed the patient data regarding the following variables: electroclinical syndromes, seizure types, patient gender, age at seizure onset, structural and electrophysiological brain abnormalities, medication history, co-morbidities, and other relevant medical and family history. $\mathrm{KD}, \mathrm{JW}$ and $\mathrm{CN}$ were major contributors in writing the manuscript. All authors read and approved the final manuscript.

This is an Open Access article distributed under the terms of the Creative Commons Attribution License (http://creativecommons.org/licenses/by/4.0), which permits unrestricted use, distribution, and reproduction in any medium, provided the original work is properly credited. The Creative Commons Public Domain Dedication waiver (http://creativecommons.org/publicdomain/zero/1.0/) applies to the data made available in this article, unless otherwise stated.

Cite this article as:

Samia P, Barr A, Levi SB, Donald KA, Wilmshurst JM, Newton CR. Clinical characteristics of children with epilepsy managed at an urban hospital in Africa: a retrospective study. JICNA [Internet]. 2019Dec.28;1(1). Available from: https://jicna.org/index.php/journal/article/view/jicna2019-162

\section{References}

[1] World Health Organization. World Health Organization: Global Health Estimates 2015: DALYs by Cause, Age, Sex, by Country and by Region, 2000-2015; Available from: https://www.who.int/healthinfo/ global\{_\}burden $\left\{\_\right.$disease/estimates/en/index2. html.

[2] World Health Organization. World Health Organization Fact sheet on Epilepsy;Available from: https://www.who.int/en/news-room/fact-sheets/ detail/epilepsy.

[3] Mbuba CK, Ngugi AK, Newton CR, Carter JA. The 
epilepsy treatment gap in developing countries: a systematic review of the magnitude, causes, and intervention strategies. Epilepsia. 2008 sep;49(9):1491503. Available from: http://www.ncbi.nlm.nih.gov/ pubmed/18557778http://www.pubmedcentral.nih. gov/articlerender.fcgi?artid=PMC3573323.

[4] Meyer AC, Dua T, Ma J, Saxena S, Birbeck G. Global disparities in the epilepsy treatment gap: a systematic review. Bulletin of the World Health Organization. 2010 apr;88(4):260-6. Available from: http: //www.ncbi.nlm.nih.gov/pubmed/20431789http: //www.pubmedcentral.nih.gov/articlerender.fcgi? artid=PMC2855595.

[5] Ngugi AK, Bottomley C, Kleinschmidt I, Wagner RG, Kakooza-Mwesige A, Ae-Ngibise K, et al. Prevalence of active convulsive epilepsy in sub-Saharan Africa and associated risk factors: cross-sectional and case-control studies. The Lancet Neurology. 2013 mar;12(3):253-63. Available from: http: //www.ncbi.nlm.nih.gov/pubmed/23375964http: //www.pubmedcentral.nih.gov/articlerender.fcgi? artid= PMC3581814.

[6] Wilmshurst JM, Kakooza-Mwesige A, Newton CR. The challenges of managing children with epilepsy in Africa. Seminars in pediatric neurology. 2014 mar;21(1):36-41. Available from: http: //www.ncbi.nlm.nih.gov/pubmed/24655403http: //www.pubmedcentral.nih.gov/articlerender.fcgi? artid= PMC5496661.

[7] Dekker PA. World Health Organization: Epilepsy, A manual for medical and clinical officers in Africa; 2002.

[8] Meinardi H, Scott RA, Reis R, Sander JW, ILAE Commission on the Developing World. The treatment gap in epilepsy: the current situation and ways forward. Epilepsia. 2001 jan;42(1):136-49. Available from: http://www.ncbi.nlm.nih.gov/pubmed/11207798.

[9] Berg AT, Berkovic SF, Brodie MJ, Buchhalter J, Cross $\mathrm{JH}$, van Emde Boas W, et al. Revised terminology and concepts for organization of seizures and epilepsies: report of the ILAE Commission on Classification and Terminology, 2005-2009. Epilepsia. 2010 apr;51(4):676-85. Available from: http://www.ncbi. nlm.nih.gov/pubmed/20196795.

[10] Scheffer IE, Berkovic S, Capovilla G, Connolly MB, French J, Guilhoto L, et al. ILAE classification of the epilepsies: Position paper of the ILAE Commission for Classification and Terminology. Epilepsia. 2017;58(4):512-521. Available from: http: //www.ncbi.nlm.nih.gov/pubmed/28276062http: //www.pubmedcentral.nih.gov/articlerender.fcgi? artid=PMC5386840.
[11] Birbeck GL. Revising and refining the epilepsy classification system: priorities from a developing world perspective. Epilepsia. 2012 jul;53 Suppl 2:18-21. Available from: http://www.ncbi.nlm.nih. gov/pubmed/22765500http://www.pubmedcentral. nih.gov/articlerender.fcgi? artid=PMC3397392.

[12] Kariuki SM, Matuja W, Akpalu A, Kakooza-Mwesige A, Chabi M, Wagner RG, et al. Clinical features, proximate causes, and consequences of active convulsive epilepsy in Africa. Epilepsia. 2014 jan;55(1):7685. Available from: http://www.ncbi.nlm.nih.gov/ pubmed/24116877http://www.pubmedcentral.nih. gov/articlerender.fcgi?artid=PMC4074306.

[13] Fisher RS, Acevedo C, Arzimanoglou A, Bogacz A, Cross JH, Elger CE, et al. ILAE official report: a practical clinical definition of epilepsy. Epilepsia. 2014 apr;55(4):475-82. Available from: http://www.ncbi. nlm.nih.gov/pubmed/24730690.

[14] World Health Organization. HIV/AIDS Definition of key terms; 2013. Available from: https://www.who. int/hiv/pub/guidelines/arv2013/intro/keyterms/en/.

[15] World Health Organization. Infant, Newborn;. Available from: https://www.who.int/infant-newborn/ en/.

[16] Burton KJ, Rogathe J, Whittaker R, Mankad K, Hunter E, Burton MJ, et al. Epilepsy in Tanzanian children: association with perinatal events and other risk factors. Epilepsia. 2012 apr;53(4):75260. Available from: http://www.ncbi.nlm.nih.gov/ pubmed/22308971http://www.pubmedcentral.nih. gov/articlerender.fcgi?artid=PMC3467761.

[17] Gebremariam A, Gutema Y, Leuel A, Fekadu H. Earlyonset neonatal seizures: types, risk factors and shortterm outcome. Annals of tropical paediatrics. 2006 jun;26(2):127-31. Available from: http://www.ncbi. nlm.nih.gov/pubmed/16709331.

[18] Kanu I, Anyanwu EC, Nwachukwu NC, Ehiri JE, Merrick J. Clinical Microbiological Aspects of Epileptic Seizures in the Tropical Countries with Specific Focus on Nigeria. The Scientific World JOURNAL. 2005;5:401-409. Available from: http://www. hindawi.com/journals/tswj/2005/859645/abs/.

[19] Munyoki G, Edwards T, White S, Kwasa T, Chengo E, Kokwaro G, et al. Clinical and neurophysiologic features of active convulsive epilepsy in rural Kenya: a population-based study. Epilepsia. 2010 dec;51(12):2370-6. Available from: http: //www.ncbi.nlm.nih.gov/pubmed/20608962http: //www.pubmedcentral.nih.gov/articlerender.fcgi? artid $=$ PMC3188844. 
[20] Nicoletti A, Bartoloni A, Sofia V, Mantella A, Nsengiyumva G, Frescaline G, et al. Epilepsy and toxocariasis: a case-control study in Burundi. Epilepsia. 2007 may;48(5):894-9. Available from: http: //www.ncbi.nlm.nih.gov/pubmed/17508999.

[21] Ogunlesi T, Ogundeyi M, Olowu A. Pattern of childhood epilepsies in Sagumu, Nigeria. Indian journal of pediatrics. 2009 apr;76(4):385-9. Available from: http://www.ncbi.nlm.nih.gov/pubmed/19205638.

[22] Ogunrin OA, Adeyekun A, Adudu P. Etiologies of epilepsy and health-seeking itinerary of patients with epilepsy in a resource poor setting: analysis of 342 Nigerian Africans. Seizure. 2013 sep;22(7):5726. Available from: http://www.ncbi.nlm.nih.gov/ pubmed/23664807.

[23] Berhanu S, Alemu S, Prevett M, Parry EHO. Primary care treatment of epilepsy in rural Ethiopia: causes of default from follow-up. Seizure. 2009 mar;18(2):1003. Available from: http://www.ncbi.nlm.nih.gov/ pubmed/18701322.

[24] Coleman R, Gill G, Wilkinson D. Noncommunicable disease management in resource-poor settings: a primary care model from rural South Africa. Bulletin of the World Health Organization. 1998;76(6):63340. Available from: http://www.ncbi.nlm.nih.gov/ pubmed/10191559http://www.pubmedcentral.nih. gov/articlerender.fcgi?artid=PMC2312489.

[25] Diop AG, Hesdorffer DC, Logroscino G, Hauser WA. Epilepsy and mortality in Africa: a review of the literature. Epilepsia. 2005;46 Suppl 1:33-5. Available from: http://www.ncbi.nlm.nih.gov/pubmed/16393176.

[26] Elechi CA. Default and non-compliance among adult epileptics in Zaria, Nigeria. The need to restructure continued care. Tropical and geographical medicine;43(1-2):242-5. Available from: http: //www.ncbi.nlm.nih.gov/pubmed/1750124.

[27] Kaiser C, Asaba G, Mugisa C, Kipp W, Kasoro S, Rubaale $\mathrm{T}$, et al. Antiepileptic drug treatment in rural Africa: involving the community. Tropical doctor. 1998 apr;28(2):73-7. Available from: http://www. ncbi.nlm.nih.gov/pubmed/9594671.

[28] Kalk WJ, Veriawa Y, Osler C. A survey of hospital outpatient services for chronic diseases in Gauteng. South African medical journal $=$ Suid-Afrikaanse tydskrif vir geneeskunde. 2000 jan;90(1):57-61. Available from: http://www.ncbi.nlm.nih.gov/pubmed/10721395.

[29] Nimaga K, Desplats D, Doumbo O, Farnarier G. Treatment with phenobarbital and monitoring of epileptic patients in rural Mali. Bulletin of the World Health Organization. 2002;80(7):532-7. Available from: http://www.ncbi.nlm.nih.gov/ pubmed/12163916http://www.pubmedcentral.nih. gov/articlerender.fcgi?artid=PMC2567553.

[30] Sanya EO, Wahab KW, Desalu OO, Bello HA, Ademiluyi BA, Alaofin WA, et al. A 3 year audit of adult epilepsy care in a Nigerian tertiary hospital (2011-2013). Annals of African medicine;14(2):97102. Available from: http://www.ncbi.nlm.nih.gov/ pubmed/25693817.

[31] Burton K, Rogathe J, Whittaker RG, Mankad K, Hunter E, Burton MJ, et al. Co-morbidity of epilepsy in Tanzanian children: a community-based casecontrol study. Seizure. 2012 apr;21(3):169-74. Available from: http://www.ncbi.nlm.nih.gov/ pubmed/22130004http://www.pubmedcentral.nih. gov/articlerender.fcgi? artid=PMC3672980.

[32] Duggan MB. Epilepsy and its effects on children and families in rural Uganda. African health sciences. 2013 sep;13(3):613-23. Available from: http: //www.ncbi.nlm.nih.gov/pubmed/24250298http: //www.pubmedcentral.nih.gov/articlerender.fcgi? artid $=$ PMC3824457.

[33] Elafros MA, Sakubita-Simasiku C, Atadzhanov M, Haworth A, Chomba E, Birbeck GL. Stigma and psychiatric morbidity among mothers of children with epilepsy in Zambia. International health. 2013 dec;5(4):288-94. Available from: http: //www.ncbi.nlm.nih.gov/pubmed/24214528http: //www.pubmedcentral.nih.gov/articlerender.fcgi? artid=PMC3850361.

[34] Koba Bora B, Lez DM, Luwa DO, Baguma MB, Katumbay DT, Kalula TK, et al. Living with epilepsy in Lubumbashi (Democratic Republic of Congo): epidemiology, risk factors and treatment gap. The Pan African medical journal. 2015;21:303. Available from: http://www.ncbi.nlm.nih.gov/pubmed/ 26587151http://www.pubmedcentral.nih.gov/ articlerender.fcgi? artid=PMC4633807.

[35] Sebera F, Munyandamutsa N, Teuwen DE, Ndiaye IP, Diop AG, Tofighy A, et al. Addressing the treatment gap and societal impact of epilepsy in Rwanda-Results of a survey conducted in 2005 and subsequent actions. Epilepsy \& behavior : E\&B. 2015 may;46:126-32. Available from: http://www.ncbi.nlm.nih.gov/ pubmed/25936276http://www.pubmedcentral.nih. gov/articlerender.fcgi?artid=PMC4464509.

[36] Ellenberg JH, Hirtz DG, Nelson KB. Age at onset of seizures in young children. Annals of neurology. 1984 feb;15(2):127-34. Available from: http://www.ncbi. nlm.nih.gov/pubmed/6703653.

[37] Ogunrin OA, Adeyekun AA. Profile of post-traumatic epilepsy in Benin City, Nigeria. West African journal of medicine;29(3):153-7. Available from: http://www. ncbi.nlm.nih.gov/pubmed/20665457. 
8] Feksi AT, Kaamugisha J, Gatiti S, Sander JW, Shorvon SD. A comprehensive community epilepsy programme: the Nakuru project. Epilepsy research. 1991 apr;8(3):252-9. Available from: http://www.ncbi. nlm.nih.gov/pubmed/1868825.

[39] Carter JA, Neville BGR, White S, Ross AJ, Otieno G, Mturi N, et al. Increased prevalence of epilepsy associated with severe falciparum malaria in children. Epilepsia. 2004 aug;45(8):978-81. Available from: http://www.ncbi.nlm.nih.gov/pubmed/15270766.

[40] Kind CJ, Newton CRJC, Kariuki SM, Neurodevelopment Disorders study group. Prevalence, risk factors, and neurobehavioral comorbidities of epilepsy in Kenyan children. Epilepsia open. 2017;2(4):388399. Available from: http://www.ncbi.nlm.nih.gov/ pubmed/29588970http://www.pubmedcentral.nih. gov/articlerender.fcgi?artid=PMC5862110.

[41] Lagunju IA, Oyinlade AO, Babatunde OD. Seizurerelated injuries in children and adolescents with epilepsy. Epilepsy \& behavior : E\&B. 2016 jan;54:1314. Available from: http://www.ncbi.nlm.nih.gov/ pubmed/26708062.

[42] Mung'ala-Odera V, White S, Meehan R, Otieno GO, Njuguna $\mathrm{P}$, Mturi $\mathrm{N}$, et al. Prevalence, incidence and risk factors of epilepsy in older children in rural Kenya. Seizure. 2008 jul;17(5):396-404. Available from: http://www.ncbi.nlm.nih.gov/ pubmed/18249012http://www.pubmedcentral.nih. gov/articlerender.fcgi?artid=PMC3428880.

[43] The World Bank. GDP per capita (current US\$) Kenya;. Available from: https://data.worldbank.org/ indicator/NY.GDP.PCAP.CD?locations=KE.

[44] Buchhalter J. Treatment of childhood absence epilepsy-an evidence-based answer at last! Epilepsy currents. 2011 jan;11(1):12-5. Available from: http: //www.ncbi.nlm.nih.gov/pubmed/21852860http: //www.pubmedcentral.nih.gov/articlerender.fcgi? artid $=$ PMC3063575. 